\title{
Social workers' perceptions of multi-disciplinary team work: A case study of health social workers at
a major regional hospital in New Zealand
}

Rebecca Giles Waikato Institute of Technology, New Zealand

\begin{abstract}
INTRODUCTION: International research has highlighted the importance of effective multidisciplinary team (MDT) functioning in health care settings: when collaboration between disciplines is effective, higher quality patient care results; whereas poor MDT functioning is associated with deleterious health outcomes. This study explores the findings of a small-scale case study into social workers' views of MDT functioning at a major, regional public hospital in New Zealand.
\end{abstract}

METHODS: Data was collected using in-depth interviews with eight health social workers and one focus group with three additional health social workers. Thematic analysis was used to identify key themes, and a discourse analysis undertaken to identify predominant discourses evident in the data.

FINDINGS: Study participants considered that when MDTs were well-facilitated important non-medical aspects of patient care were addressed: patient care and discharge plans were communicated clearly and consistently to patients and families, and coordination between MDT members was effective. However, participants also identified occasions when the facilitation of MDTs was poor, where meetings were unstructured and unfocussed, and where social work and patient concerns with wider non-medical issues was devalued. Participants considered that such situations could lead to confusion and distress for patients and a failure to coordinate effective plans for discharge.

CONCLUSION: The findings from this case-study suggest that, from the perspective of health social workers, ineffective facilitation of MDTs, an undue emphasis on the discourse of the patient as a 'site of disease', and a preoccupation with the management of risk can demote and devalue more holistic patient-centred perspectives, and the effectiveness of important, nonmedical aspects of patient care.

KEY WORDS: multi-disciplinary teams; interdisciplinary communication; health social work; medical discourse

\section{Introduction}

A multi-disciplinary team (MDT) is a group of health professionals from different disciplines working in particular settings such as wards, clinics, rehabilitation centres, assessment centres, or delivery suites. The term inter-disciplinary collaboration is used in this study to refer to the process of working togther within an MDT and is defined by Bruner (1991) as "...an effective interpersonal process that facilitates the achievement of goals that cannot be reached when individual professionals act on their own"
AOTEAROA

NEW ZEALAND SOCIAL WORK 28(1), 25-33.

CORRESPONDENCE TO: Rebecca Giles rebecca.giles@wintec.ac.nz 
(cited in Bronstein, 2003, p. 299). Studies indicate that the functioning of MDTs can have important consequences for patient outcomes. Poorly functioning MDTs have been associated with negative outcomes for the safety of surgical patients; and for patient care, and infant mortality, in maternity delivery suites (The Joint Commission, 2004, as cited in Zwarenstein, Goldman, \& Reeves, 2009). A systematic review by Zwarenstein, Goldman and Reeves (2009) highlighted the positive impact on outcomes for patients when MDT functioning is high. Zwarenstein et al (2009) argue that the effective functioning of MDTs is such a significant factor for patient care that they ought to be subject to routine monitoring and evaluation.

The focus of this study is on the functioning of MDTs as perceived by one disciplinary group: health social workers. A US study by Liepzig, Hyer, Wallenstein, Vezina, Fairchild, Cassel and Howe (2002) found that, in comparison with other disciplines, social workers were more likely to have been trained to value inter-professional collaboration, had more knowledge of it, more experience and skills in collaboration, and held higher expectations of the value of working in teams and groups. That health social workers place a high value on teamwork and collaboration is supported by Haultain's (2013) practice framework for health social work where "develops and maintains relationships with the MDT for the benefit of our patients and their families" (p. 45) is one of eight key practice domains. In addition, social workers bring important social, cultural and community perspectives to the work of the MDT. There is a complex but well-established relationship between the health and well-being of individuals, families and communities and a wide range of social, economic and cultural factors. Health researchers are aware that factors such as poverty, poor housing, and unemployment are significantly associated with negative health outcomes (Bambra, Fox \& Scott- Samuel, 2005; WHO, 2011).
Therefore, as members of MDTs, it seems likely that social workers can potentially contribute both process skills for effective inter-disciplinary collaboration, and an understanding of the wider social, familial and cultural context for the ongoing assessment and care of the patient (Connolly \& Harms, 2009). Yet whether these potential contributions are actually realised depends on the functioning of the MDT and, importantly, on the prevailing discursive regime within particular health care settings.

Opie (1997) has advocated the use of critical perspectives to aid understanding of what occurs within MDTs. Her research focuses on the way dominant discourses create power dynamics that significantly influence the functioning of the MDT. Foucault (1978, as cited in Opie, 1997) identified the influence of discursive power in institutional settings, such as hospitals, and the way in which particular disciplinary discourses are privileged and can come to dominate and disempower other disciplines within the same setting. The hierarchical context that this dominance engenders means that some MDT members may find they are not positioned equally when it comes to influencing decisions such as establishing the priorities for discussion or work.

In their research into the influence of different disciplines within MDTs, Atwal and Caldwell (2005) argue that when disciplinary groups are perceived to have unequal status, the dominant group can define expected standards of performance and techniques in ways that limit the contribution of other groups. Other points of view can be rendered invisible, and important perspectives on improving patient care may not surface when team members are perceived as, or perceive themselves to be, less entitled to speak. When relevant knowledge, skills or perspectives are not able to be contributed, then team effectiveness is weakened and patient care may be compromised. 
One aspect of the predominant medical discourse that pervades hospital and other health settings has been described by the anthropologist Good (1994) as founded on a Western medical model where the patient is viewed as a 'site of disease': a project to be worked on with scientific expertise. Good (1994) details the way in which this medical perspective - narrowly focused on the disease process - is constructed, and the way in which the wider concerns of patients can be disregarded as "not the important stuff" (p. 78) or "missing the point" (p. 79). He argues that case presentations, and other aspects of the medical world, shape thinking about, and the construction of, the person as a patient, a document, and a project. This perspective is both reflected in and shaped by conversations with and about the patient (Good, 1994, p. 78). According to Opie (1997) this narrow focus on the patient as a 'site of disease' pervades the language used in MDT discussions, and seriously limits the quality and effectiveness of their work. Her study identified that when the medical discourse predominates, then team discussions focus on the physiological and medical needs of patients. The emphasis shifts towards things to be done to the patient in order to resolve the anxieties and concerns of MDT members. When this occurs then other, more social and contextual, patient concerns or perspectives can be significantly overlooked.

The idea of MDT members intervening to relieve their own anxieties and concerns is related to the concept of risk in contemporary health settings. Critical theorists refer to our contemporary preoccupation with risk and characterise attempts to manage risk as way of attempting to control the future (Giddens, 1999). Pollack (2010) points out that "The impact of risk in health and social policy promotes a greater emphasis on the defensibility of decisions rather than making good decisions" (p. 1274). One outcome of an overzealous consideration of risk is that, it can lead to oppressive practice based upon highlighting the deficits of patients (Brown, 2011 as cited in Beddoe, 2014). In health institutions risk aversion is associated with the prevalence of techno-rational processes, protocols and audits to provide quantifiable evidence; and with 'paper trails' and check lists aimed at minimising the risk of 'something important being missed'. Social workers are commonly involved in cases where there may be concerns regarding risk and safety, and sometimes find themselves pressured to practice defensively. Beddoe (2014) urges that, in these situations, in order to maintain an ethical, client-centred focus that promotes self-determination and human agency, social workers must practice critically and reflectively.

This study aimed to explore the views that social workers held about the functioning of MDTs. The overall research question for this study was how do social workers perceive the functioning of multi-disciplinary teams in the hospital context? The objectives of the study were to explore health social workers' perceptions in order to:

- develop a social work perspective on the effectiveness of work within the multidisciplinary health care teams

- identify social worker's views on examples of effective team functioning that benefit services to clients

- examine the components of effective MDT functioning from the social workers' perspectives

- identify areas of poor team performance from the social work perspective and consider causes and solutions for this.

\section{Methods}

This study is a small-scale, qualitative case study exploring the perceptions of social workers from within a single team in a major regional public hospital in New Zealand. In-depth qualitative data was collected using individual interviews with eight social workers, and a focus group discussion including an additional three social workers. The sampling was a convenience sample and 
all 16 social workers from the hospital's acute social work team were invited to participate.

The research objectives described above were used to devise a series of open-ended questions as prompts for discussion during the interviews. A similar set of questions was created for the focus discussion group. Interviewees were informed that all research outputs would be made anonymous to reduce the chance of attribution to specific social workers. They were also given copies of the relevant transcripts and informed that they could change or delete material, or withdraw their contribution completely, should they wish to do so before it was integrated into the study.

The material recorded from the interviews and focus group discussion was transcribed verbatim by the researcher, providing an opportunity to become very familiar with the material. The method utilised for the thematic analysis involved a process of data reduction, data organisation and data interpretation. In developing the themes the original research question and objectives were kept in mind (Tolich \& Davidson, 2011).

The discourse analysis section of this study draws its theoretical base from Michel Foucault's (1978) work which focuses upon discourses present within institutional spaces that result in the privileging of certain disciplines and discursive practices over others. Medical anthropologist Good (1994) also aids the analysis through illuminating understanding of the cultural and discursive features of medical discourse. In critically analysing the social workers 'material the guidance of Fairclough (1989) is also drawn upon.

The study was conducted as part of a Masters of Education at the University of Waikato. Ethical approval was gained from the University of Waikato, Faculty of Education Ethical Committee, Waikato Hospital Ethics Committee and the Māori Advisory Services to Waikato District Health Board: Te Puna Oranga.

\section{Findings}

The findings are presented in two parts, with part one derived from the thematic analysis of the data; and part two from a discourse analysis.

\section{Thematic Analysis}

A thematic analysis of the interview and transcript data identified the following themes: the format of MDT meetings; the ethos of MDT collaboration; the problem of disciplinary terminology; the involvement of doctors; positively and poorly functioning MDTs; complex cases; and the social work role in MDTs.

\section{MDT Format}

Participants reported that, at the hospital studied, interdisciplinary communication is conducted using a range of formats including: scheduled weekly MDT meetings; one-off meetings to discuss specific patients; team members communicating regarding specific patients via the patients' medical records; and team members contacting one another individually to consult using face-to face, phone conversations, email and texting.

\section{The ethos of MDT collaboration}

Research participants emphasised that, when there is an ethos that values inter-disciplinary collaboration, the work of the MDT can be very effective. One participant stated that

Acute medical ward meetings can go really well if there's a Charge Nurse Manager who really wants a collective input, where there's others who just want to race through and tell you who needs to be seen as opposed to having a discussion about patients.(Participant \# 1: Individual interview)

\section{The problem of disciplinary terminology}

A hugely diverse range of professionals can be present at MDT meetings, 
including senior doctors and nurses, doctors and nurses in training, particular doctor and nurse specialists, researchers, physiotherapists, dieticians, social workers, occupational therapists, speech therapists, midwives, home care coordinators and others. Different disciplines can have very different terminology and ways of communicating adding complexity to the process, as this comment indicates:

You could use the same words but you are looking at a different thing......... the same terminology but the background thinking or theory behind it is different..... you could actually have a conversation thinking you are talking about the same thing but you're not. (Participant \#2: Individual interview)

\section{The involvement of doctors}

All participants commented that, when doctors are not present in MDT activities the quality of patient care may suffer. They noted that when some of the key interventions were of a non-medical nature, it was important that doctors were present in order to listen to the plans and convey them to patients and their families. They felt that the perceived status of doctors, and families deference to medical opinion, meant that is was important that doctors understood the non-medical information. Concern was voiced that when patients are discharged without consideration of significant nonmedical concerns, that their health, wellbeing and safety may be significantly impacted. This occurs when doctors do not read notes by non-medical team members and have not been part of discussions with other disciplines.

Often medical teams will miss the material in the notes and miss recommendations in fact all sorts of different things will be recommended in the notes that counter one another - that's why we need to meet and why everyone including the doctors need to be able to discuss together. (Participant \#3: Individual interview)

\section{Positively functioning MDTs}

Positive outcomes when MDTs are functioning effectively were described by the social workers including discharge and care plans that accurately reflect patients' needs and situation, and patients knowing as much as possible about what is happening, so they can plan for discharge. All MDT staff need to be up-to-date and confident about the overall direction of care including any alternative plans that have been considered and why they may not have been actioned. A small number of participants described the enjoyment of being part of a team when their input was valued, work was effective and time was used efficiently.

\section{Poorly functioning MDTs}

Participants discussed examples of MDT meetings where team functioning was perceived to be poor and identified the factors they thought were involved. These included meetings that were unstructured and unfocused, meetings where even basic activities (such as introductory rounds) did not occur. They described meetings that were continually interrupted, where phone calls were taken, where more than one conversation happened at once, where some members dominate, or where there is confusion about who and what is being discussed. They also noted instances where stresses, or concerns from other situations were brought into the MDT meeting. Significantly, one social worker stated that, it was not uncommon for team members to sit silently throughout meetings. Frustration was expressed by a number of participants at the time wasted when meetings were poorly coordinated.
Very often people don't know who people are and what their roles are, and there's a focus on charging through meetings without clarifying that we are all on the same page and allowing an opportunity for people to add to that. (Participant \#1: Individual interview)

Participants described team meetings where the purpose was not clarified. A common 
complaint was that meetings were mostly focussed on medical or nursing issues and that no encouragement or structure was provided.

The CNMs (Clinical Nurse Managers) see it as a way of overseeing what's where and making sure they haven't forgotten anything, so it's more about their work. (Participant \#4: Individual interview)

When MDTs are not functioning effectively, the transmission of basic information and processes can become confused, and this can be reflected in the work. One social worker commented that when MDTs are not functioning effectively, it was not uncommon for patients to encounter a consecutive stream of professionals with each one reporting a different plan, resulting in distress and confusion for patients. Some social workers stated that, as a result of poor communication at MDT meetings, arrangements for important follow-up support can be missed, sometimes resulting in discharged patients facing re-admission.

\section{The social worker's role in MDTs}

The participants described the inter-related components of the social work role in MDTs including: coordination between patient, family, community agencies and MDT members; ensuring care and discharge plans are grounded in the reality of peoples' lives by representing wider contextual concerns that will impact on health or recovery; supporting communication between medical staff and patients and family (which can include slowing down discussion to ensure that patients and families understand and have an opportunity to express their concerns). One social worker emphasised the need to ensure that communication is patient-centred. Participants referred to the ongoing need to be ready to advocate and draw attention to concerns regarding drug and alcohol addictions, child protection and family violence.

Most of the interviewees commented that, as trained facilitators, social workers are willing and able to facilitate MDT meetings. One social worker commented that because the social work role often sits at the centre of the work of other professionals, they are in an ideal position to facilitate MDT meetings.

\section{Discourse Analysis}

In this section, the same data was analysed to identify key discourses. It is easy to assume that health professionals' discussions are aimed primarily at benefiting patients. However, the medical anthropologist Fairclough (1999) claims that when professionals discuss patients there are multiple, competing considerations present that are often unrelated to concerns regarding the patient. He describes the unspoken narratives that are present "inside peoples' heads" when they talk. For example, managing a busy ward, bed management, anticipated case presentations to colleagues, concerns that derive from power dynamics within teams, or teaching responsibilities between senior and junior staff. In the analysis of data from this study there were two main discourses identified: the patient as a 'site of disease'; and the discourse of risk.

\section{The patient as a 'site of disease"}

When patients are named as if they are a body part, surgical procedure, or mechanical function, the discourse that positions them as a 'site of disease' is evident. Below, a social worker comments upon the narrowness created by this thinking using a tunnel as a metaphor:

That does happen quite regularly where there's tunnel vision. You've done your piece, you've looked at this organ or from PT (physiotherapist) view can they walk? and if they can't walk, do they need an aid? ...so their focus is just on that and they will make a recommendation just on that and you think but there is all these other factors, but according to PT "discharge home"! 
Opie's (1997) research focused upon the ways in which MDTs discuss their work with patients. One of her main findings is that when teams use mechanistic ways of describing their work the 'site of disease' discourse can dominate discussion. In the comment that follows, the social worker describes the way she attempts to generate discussion about patient well-being. However, her invitational questions are assumed to refer to a task-related response (a referral to the social worker):

They will say this person is on the Liverpool Pathway, so the nurse will try to just flick over them because the Liverpool Pathway is very prescribed and they think "that's sorted, put it to the side". So then I would try to bring up "How's the family doing? Do they need any support? and then they might say

"Oh do you want to see them?"

Opie (1997) argues that when teams talk about their work in terms of narrow descriptive tasks, rather than using analytical patient-centred perspectives, opportunities to consider other options for the work of the team are blocked and quality can be reduced significantly. The following comment highlights the way in which a narrow reductive view is particularly ineffective when cases are socially and medically complex.

I find there's reality: complex issues are complex! That's just the reality of it! And somehow we want to simplify it (because) we want one little diagnosis but we actually can't and aren't ever going to have to make it simple.

\section{The discourse of risk}

The presence of risk discourse is significant in health institutions and services, creating practice based on defensibility rather than quality, and sometimes inviting practices that are oppressive. Population groups that are especially associated with the discourse of risk include: babies, children, clients with mental health histories, and adults with physical disabilities (Beddoe, 2014). The risk discourse draws attention to patients' deficits and the risks they pose to themselves or others. Such discourses can be based upon reactive stereotypes, prejudices and biased assumptions.

In the hierarchical environment of many health settings, social workers' knowledge can be devalued creating pressure to respond to risk defensively. In these instances, social workers need to promote their expertise and experience. This social worker outlines well the competing challenges that can be present:

I found that the CNM can be quite judgmental, especially if it's someone like a mental health patient. Some of the nurses can be very judgmental right from the start so it makes it difficult to work with them around best outcome for the client because they have a particular view of this client so you try to get the best outcome for the client but there's this bias. That makes it really difficult to work in a team.

The following comment illustrates a social worker countering the pressure to act in a risk averse, defensive fashion, and instead completing an assessment from a critically informed perspective, including the development of client-centred rapport.

It's about taking that more holistic view of a client and advocating for them if necessary, being open minded as to what is the best outcome for this client and that can be quite an interesting dance. You've got to listen to the opinion (of staff) because it could be a safety issue for a child but at the same time you don't want it to be clouding your judgement or your perception. We are there to advocate for our client and have empathy, empathy is a big one because sometimes that is missing from the nurses so if we get our chance we introduce that to the conversation, the discussion about the client - the client's voice.

Social workers have a history of advocacy for people experiencing harm and abuse within 
public institutions. They continue to have a professional and ethical focus, challenging processes that are unfair, dangerous or disadvantageous to people and this is evident in the comment that follows:

Because we often get women who come in and go directly to theatre and then go straight home and may have come straight through ED really quickly and have not been properly assessed for family violence. Or young men with assault injuries and so it's about trying to find out whether there are children involved which is not often asked. It may be quite a significant fight at home so there can be a teaching role for the social worker as well, giving people the things outside of just the medical.

\section{Discussion}

The findings of this study concur with prior studies that highlight the problematic nature of MDTs when medical discourse predominates and when interdisciplinary team communication is less than effective. The health social workers participating in this study considered that MDTs produce positive outcomes when teams collaborate effectively. Participants were of the view that effective MDTs could result in: better coordinated and more accurate patient care plans; planned and coordinated patient discharges; better postdischarge arrangements; appropriate and individualised transfers to other facilities; patients' expectations of discharge dates confirmed earlier; care plans that are relevant; and team members that are kept up-to-date with patient care issues.

On the other hand, when MDTs do not operate effectively, participants considered that patients can experience distress and confusion and are prone to receive very different reports regarding plans for them. Important follow-up work can be missed resulting in patient readmissions, complaints and further distress. In particular, when medical team members did not attend MDT meetings, the health social workers in this study were of the view that this signified that non-medical information and perspectives were unimportant.

The effective facilitation of MDT meetings is a key component of MDT functioning. MDT facilitation is complex, but research shows that when done well it has a positive effective on successful MDT work, improving team members' practice (Atwal \& Caldwell, 2005; Cheater et al., 2005;

Zwarenstein et al., 2009). In this study participants referred to many examples of MDTs that were poorly facilitated with a common concern being that meetings did not have a multi-disciplinary collaborative focus and were instead highly medically or nursing oriented. When discussion regarding the purpose of meetings does not occur, there is a risk of meetings being diverted to the purpose of ward management rather than inter-disciplinary collaboration for effective patient care. In addition, when the facilitation of team meetings is automatically conferred upon lead medical or nursing personnel the potential expertise of social work team members is overlooked.

\section{Study limitations}

One limitation of this study was that it was an example of insider-research, with the researcher being a health social work practitioner from within the same team as the study participants. Although this could be considered a limitation, in the sense of being open to interpretive bias, according to Fook (2002), such insider-research can also provide a unique insight into the lived experience of study participants, and offers an opportunity for the development of theory informed by reflections on everyday social work practice. A second limitation derives from the small-scale, case-study nature of the study: it included only 11 social workers from one regional hospital. Although suggestive of issues for health social workers participating in MDTs in the wider health care system, it cannot be considered to be representative. 


\section{Conclusion}

When harnessed effectively, the expertise of health social workers can make a valuable contribution to the effectiveness of MDTs. Skilled social workers can empower patients to be more in control of their health journey within the hospital setting. They can acknowledge and validate the experiences of patients, and support communication with health professionals, especially when cases are complex. The narrow 'site of disease' discourse is a powerful one within medical settings and can come to predominate in complex cases when the work of the MDT is governed by the clinical aspects of patient care, and the management of risk. Yet, the evidence from this study, suggests that an undue emphasis within MDTs on the discourse of the patient as a 'site of disease' can demote and devalue the more holistic perspective of social workers, and that the quality of patient care may be diminished as a result. This is especially critical when patients are discharged back to the community with insufficient consideration of the important social, family, cultural and community dimensions of care. Harnessing the expertise of social workers within MDTs, and their commitment to critically aware, anti-oppressive client-centred practice, could help to empower the voice of the patient and ensure a more holistic approach to patient care. Enabling social work team members to play a more active role in the facilitation of MDT meetings may also help to enhance interdisciplinary communication and MDT functioning. Further research into the practical ways in which health social workers might be supported to play a more active role within MDTs is required.

\section{References}

Atwal., A. \& Caldwell, K. (2005). Do all health and social care professionals interact equally?: A study of interactions in multidisciplinary teams in the United Kingdom. Scandinavian Journal of Caring Sciences, 19, 268-273.

Atwal, A. \& Caldwell, K. (2006) Nurse's perceptions of multidisciplinary team work in acute care. International Journal of Nursing Practice, 2006; 12, 359-365. doi:10.1111/j.1440-172X.2006.00595.x
Bambra, C. Fox, D., \& Scott-Samuel, A. (2005). Towards a politics of health. Health Promotion International. 20(2), 187-193. doi:10.1093/heapro/dah608.2005.2.18

Beddoe, E. (2014) Risk and vulnerability discourses in health. In L. Beddoe \& J. Maidment (Eds.), Social work practice for promoting health and wellbeing: Critical issues (pp. 51-62). Oxon: Routledge.

Bronstein, L. (2003). A model for interdisciplinary collaboration. Social Work. 48(3), 297- 306.

Cheater, F. M., Hearnshaw, H., Baker, R., \& Keane, M., (2005). Can a facilitated programme promote effective audit in secondary care teams: An exploratory trial. International Journal of Nursing, 42 (2005) 779-791 doi:http://dx.doi.org/10.1016/j.ijnurstu.2004.11.002

Connolly, M., \& Harms, L. (2009). Social work: contexts and practice (2nd ed.). South Melbourne, Victoria: Oxford University Press Australia and New Zealand.

Fairclough, N. (1999). Linguistic and intertextual analysis within discourse analysis. In A. Jaworski \& N. Coupland,(Eds.), The discourse reader (pp. 183-211). London, UK: Routledge.

Giddens, A. (1999). Risk and responsibility. Modern Law Review, 62(1), 1-10. doi:10.1111/1468-2230.00188

Good, B.J. (1994). Medicine, rationality and experience: An anthropological perspective. Cambridge University Press: New York.

Haultain, L. (2013). Facing the challenges together: Future vision for health social work. In E. Beddoe \& J. Maidment (Eds.), Social work practice for promoting health and wellbeing: Critical issues (pp. 39-50). Oxford: Routledge.

Liepzig, R.M., Hyer, K., Wallenstein, S., Vezina, M., Fairchild, S., Cassel, C.K., \& Howe, J.L. (2002). Attitudes toward working on interdisciplinary healthcare teams: A comparison by discipline. Journal of the American Geriatrics Society, 50(6), 1141-1148.

Opie, A. (1997). Thinking teams thinking clients: Issues of discourse and representation in the work of health care teams. Sociology of Health \& IIIness. 19(3), 259-280 doi:10.1111/j.1467-9566.

Pollack, S. (2010). Labelling clients 'risky': Social work and the neo-liberal welfare state. British Journal of Social Work, 4O(4), 1263-1278. doi:10.1093/bjsw/bcn079

Tolich, M. \& Davidson, C. (2011). Getting started: An introduction to research methods. Auckland, New Zealand: Pearson New Zealand.

World Health Organisation (2011). World conference on social determinants of health: Closing the gap: Policy into practice on social determinants of health. Discussion paper. Rio de Janeiro, Brazil: Author. Retrieved from http://www.who.int/sdhconference/ Discussion-paper-EN.pdf

Zwarenstein, M., Goldman, J. \& Reeves, S. (2009). Interprofessional collaboration: Effects of practice-based interventions on professional practice and healthcare. Cochrane Database of Systematic Reviews, 3, 1-30. doi:10.1002/14651858.CD000072.pub2 